\title{
La Guerra de Arauco como materia predicable: Sermón y política en la obra de fray Juan de Barrenechea y Albis ${ }^{1}$
}

\section{The Arauco War as a Preaching Matter. Sermon and Politics in the Work of Friar Juan de Barrenechea y Albis}

\author{
STEFANIE MASSMANN \\ ROCÍO RODRÍGUEZ FERRER \\ Universidad Andrés Bello, Chile. \\ Correo electrónico: smassmann@unab.cl \\ Pontificia Universidad Católica de Chile. \\ Correo electrónico: rcrodrif@uc.cl
}

El artículo propone una lectura a la luz de las artes predicativas de la crónica La Restauración de La Imperial y conversión de las almas infieles (h. 1693) del fraile mercedario criollo Juan de Barrenechea y Albis. Postulamos que el texto se configura desde los preceptos del discurso eclesiástico y, en particular, del sermón como género especialmente significativo en las llamadas crónicas de Indias. Para abordar la deuda de la escritura de Barrenechea y Albis con la retórica predicativa analizaremos principalmente la instrumentalización del exemplum como arma de persuasión; por otra parte, proponemos que el uso de la retórica predicativa no solo está al servicio de objetivos espirituales, sino que se relaciona con la exposición de una visión polémica sobre la Guerra de Arauco y con la participación de discusiones políticas y teóricas que le son contemporáneas.

Palabras claves: Fray Juan de Barrenechea y Albis, sermón y literatura, retórica predicativa, literatura colonial, Guerra de Arauco.

This essay analyzes La Restauración de La Imperial y conversión de las almas infieles (h. 1693) by creole Mercedarian friar Juan de Barrenechea y Albis as part of the preaching rhetoric displayed not for the salvation of the souls, but for influencing policies regarding the Arauco War. We argue that the novel, which is included in the text, demands to be read as an exemplum to persuade about the importance of the evangelization in order to bring peace to Chile -an unpopular posture back then-.

Key words: Friar Juan de Barrenechea y Albis, literature and preaching, preaching rhetoric, colonial literature, Arauco War.

\footnotetext{
${ }^{1}$ El artículo forma parte del proyecto de investigación Fondecyt Regular 1160968: "Estudio y edición crítica anotada de La restauración de La Imperial y conversión de las almas infieles" (h. 1693) de Juan de Barrenechea y Albis", cuya investigadora responsable es Stefanie Massmann. Co-investigadoras: Lucía Martínez y Rocío Rodríguez Ferrer.
} 


\section{INTRODUCCIÓN}

La obra que nos dejó el mercedario criollo Fray Juan de Barrenechea y Albis ${ }^{2}$ y que constituye el objeto de este trabajo, presenta particularidades de gran interés para el estudioso de las letras coloniales: la erudición que despliega sobre las más diversas materias y hechos, el uso abundante de citas y una textura retórica que se alimenta de tradiciones diversas. Nuestro trabajo se propone despejar precisamente algunos rasgos distintivos de su escritura en relación con la retórica predicativa, siempre con el interés de vincular esta con los sentidos que el autor intenta construir en diálogo con su tiempo. El texto del que hablamos se conoce como La Restauración de la Imperial y conversión de las almas infieles, que se terminó de redactar hacia el año 1693 y narra acontecimientos históricos acaecidos en el Reino de Chile entre el inicio de la conquista y fines del siglo XVII. Incluye, asimismo, disertaciones morales, teológicas y políticas, relatos históricos y testimoniales, además de una novela de amores mapuche conocida como "Aventuras y galanteos de Carilab y Rocamila", de gran importancia en el ámbito de la prosa colonial, por tratarse, en opinión de Menéndez y Pelayo (1943), de "uno de los rarísimos [ensayos de novela] que se hicieron en toda América" (xlii-xliii). La parte de la crónica que corresponde a la novela fue publicada por José Anadón, en 1983, con el título de La novela colonial de Barrenechea y Albis. Siglo XVII. Aventuras y galanteos de Carilab y Rocamila; el manuscrito con el resto del texto conservado se encuentra en el Archivo Nacional de Chile, volumen 39, y consta de 314 folios. Además de su adaptación de singulares moldes literarios que hemos estudiado en otro momento (Massmann y Rodríguez Ferrer 2015), la obra en su totalidad se configura, ante todo, desde los preceptos del discurso eclesiástico y, en particular, del sermón como género especialmente significativo en la producción letrada de las llamadas Indias. Para demostrarlo, señalaremos primero brevemente algunas deudas del texto de Barrenechea y Albis con la retórica predicativa, para luego analizar la instrumentalización del exemplum como arma de persuasión y la utilización de la retórica predicativa en el contexto de la polémica sobre la esclavitud y la guerra en el Reino de Chile.

\footnotetext{
${ }^{2}$ Según noticia de José Anadón (1983), Juan de Barrenechea y Albis nace alrededor de 1638 en Concepción, Chile; sus antepasados, de acuerdo a la propia declaración del fraile, habían seguido carrera militar, y más adelante la familia se estableció en Chillán, en donde tenían una encomienda. Pasó su infancia y juventud en tierras fronterizas, pues declara que en 1655, en el momento del segundo levantamiento general de los indígenas, él se encontraba nuevamente en Concepción. Incluso una vez que entró a estudiar al colegio de los Mercedarios en Santiago en 1656 viajaba con frecuencia a sus tierras natales (Anadón 25), pues estaba precisamente en Concepción para el gran terremoto y maremoto de 1657. En 1664 se ordenó sacerdote y con el tiempo ocupó altos cargos, como el de catedrático de Teología en el colegio de Santiago, provincial mercedario en Santiago entre 1678 y 1681 y calificador de la Inquisición. Es probable también que completara los estudios que recibió en Chile con formación superior en la Universidad de San Marcos en Lima, lo que da cuenta de una educación relativamente esmerada, si se considera que su lugar de origen no es solo el Reino de Chile, sino que una ciudad fronteriza. Según Lucía Martínez (2015), esta educación, si bien no completa ni sistemática, permitió al mercedario conocer una norma lingüística muy cercana a la peninsular y producir "una obra especialmente culta de la producción chilena colonial que se caracteriza por un registro formal” (87).
} 
Una lectura que ponga en diálogo crónica y predicación nos permitirá atender, desde una nueva perspectiva, a aspectos centrales de la narrativa de Barrenechea y Albis, como su carácter ejemplar y su supeditación a propósitos religiosos y políticos. Asimismo, visibilizará una particularidad de las escrituras coloniales que reclama aún una mayor atención: la presencia del sermón en textos de carácter histórico, administrativo y/o literario ${ }^{3}$. En este caso en particular, ponderaremos especialmente el modo en que la novela de amores mapuche que cobija la crónica del mercedario criollo profita de formas auxiliares catequéticas para ofrecer una solución a la problemática de la alteridad en situación de frontera.

\section{ARS PRAEDicandi COMO MODELO RETórico}

Examinar la influencia de la predicación en la obra del mercedario criollo Juan de Barrenechea y Albis nos permite interpretar de mejor manera su obra. Como sacerdote, la predicación es una praxis verbal que el autor practica, ensaya y conoce, y que sin duda alguna juega un rol importante en la configuración de La restauración de La Imperial y conversión de almas infieles. La relación entre las crónicas y las artes predicativas ha sido resaltada por la crítica, aunque muchas veces ignorada a la hora de aproximarse a una obra desde la perspectiva literaria. La obra de Barrenechea y Albis, a pesar de estar escrita por un mercedario, no ha sido puesta en diálogo con la predicación, aunque esta fuese, probablemente, la forma discursiva que nuestro autor practicara con mayor asiduidad, como corrobora José Anadón (2017) al señalar que "el fraile tuvo fama de buen predicador y en 1668, en Lima, imprimió uno de sus sermones" (235) .

Disponemos de antecedentes relevantes para discutir sobre escrituras coloniales y sermón. Rolena Adorno (1990) ha destacado la importancia de la retórica eclesiástica (182), y Carlos Herrejón (1994) entrega contundentes datos sobre la práctica del sermón en la Nueva Espańa que nos pueden dar una idea de la familiaridad de los lectores con este tipo de discurso durante la época colonial. Herrejón señala que "[p]odemos decir que el discurso retórico, particularmente el sermón, fue el género más cultivado e impreso en la Nueva Espańa” (59), lo que se refleja en una cifra aproximada de más de 2.000 obras impresas de

\footnotetext{
${ }^{3}$ Ana Castaño Navarro (2008) ya ha llamado la atención sobre este hecho en su artículo "Sermón y literatura. La imagen del predicador en algunos sermones de la Nueva España”. Allí destaca algunas contribuciones de gran relevancia en la historia del sermón en España, entre las cuales se encuentran los cuatro volúmenes de la Oratoria sagrada en los siglos XVI y XVII (Madrid: Fundación Universitaria Española, 1996-2004) y, ya en el ámbito novohispano, el libro de Perla Chinchilla Pawling (2004), De la Compositio Loci a la República de las letras. Predicación jesuita en el siglo XVII novohispano. Los trabajos de Carlos Herrejón (1994) y Bernarda Urrejola son, asimismo, muy relevantes en el estudio del sermón en el ámbito novohispano. Con todo, la pregunta por la influencia del sermón en las letras coloniales hispanoamericanas tiene todavía amplias posibilidades de desarrollo.

${ }^{4}$ Gracias a José Anadón podemos ver este sermón que se encuentra en la Sala Medina de la Biblioteca Nacional bajo la signatura Impresos 11-50 (31).
} 
oratoria en el México novohispano. No obstante, el sermón era primordialmente oral, como lo era también la cultura de la época: "[e]l sermón era medio de comunicación privilegiado, frecuentísimo, autorizado y obligado" (60). Los sermones que se imprimieron en Nueva España -sermones elaborados, escritos por predicadores renombrados- estaban dirigidos principalmente a la población espańola (tanto letrada como popular), y no a la indígena con fines de evangelización misionera (Herrejón 62, Castaño 2008: 200) ${ }^{5}$. Como es de esperarse, en los siglos XVII y XVIII se caracteriza por el estilo barroco de gran potencial simbólico, en sintonía con una sociedad que quiere mostrar erudición e ingenio en su relación con tradiciones clásicas y cristianas (Herrejón 70); estas prácticas están asociadas, a su vez, con la regulación de normas sociales y la legitimación de la estructura social imperante (Witschorik 2013: 19).

Un hecho que autoriza la lectura de la novela intercalada en la obra del fray Juan como un exemplum propio del sermón, es la comprobación de que la obra toda -y no solo el relato intercalado- está infiltrada de una retórica predicativa. Un primer aspecto en este sentido dice relación con el hecho ya mencionado del carácter primariamente oral del sermón. La interpelación directa al auditorio, los diálogos y apóstrofes permiten al predicador crear escenas vivas para captar la atención de los oyentes (Iraceburu Jiménez 2016: 736, Castaño 196-198). La abundancia de preguntas retóricas, de exclamaciones y de diálogos directos es una constante en la obra de Barrenechea y Albis, tanto en la novela sobre Carilab y Rocamila como en el resto del texto, en especial cuando acomete comentarios bíblicos. En ocasiones, las preguntas retóricas, diálogos y exclamaciones pueden apilarse oración tras oración con el fin de lograr impresionar al auditorio, como sucede en el siguiente ejemplo de discurso directo que sale de boca de Rocamila cuando conoce el cautiverio de Carilab:

¡Ay, ay, amarga de mí! - dice desahogando en lágrimas y suspiros su tierno corazón más ahogadas en la garganta, anudada las sentidas quejas- No es libertad -decía dolorosa- la que tu brío me dio, querido esposo mío. Ni es dada, Carilab, si me sale a tanto costo. Si se ha comprado con el valor de una vida, que en más que la mía aprecio, ¿para qué fue libertarme dejándome más cautiva y padeciendo mil muertes, cuando me falta la luz de la vida de que vivo? No fuera yo del pirata rigoroso, la cautiva: pues cautiva, ya lo estaba y tu vida en libertad viviera con la esperanza de que vivía el amor en tu pecho generoso. ¿Qué de este triste corazón agora hará la desdicha mía? Cuando ya la imagen de esperanzas muertas a que se doblan celebrando exequias los suspiros, quiebra con rigor de mi vital estambre el lazo tierno. Ya muero, desapiadados los cielos. ¡Oh, crueles hados míos! ¿Qué crueldades son estas? Bien me anunciaban fatales los sueños horrorosos tanto mal como el que lloro. Mas el bruto que miraba ensangrentado fue el que ha librado mi

\footnotetext{
${ }^{5}$ Carlos Herrejón revisa los sermones impresos de los siglos XVII y XVII en Nueva Espańa y los clasifica del siguiente modo: los más frecuentes, representando más de la mitad de la muestra, son los panegíricos; le siguen los de honras fúnebres con aproximadamente un cuarto de la muestra y luego, con una frecuencia menor, los morales, de acción de gracias y de diverso tipo (63).
} 
vida. ¿QQué enigma es este? Decidme pues, cisne hermoso, ¿adónde está tu dueño y el que lo es de mi vida? Bañado en púrpura te vi cuando la imagen del sueño y agora en lágrimas mías ... (18v-19r $)^{6}$.

El monólogo de Rocamila se extiende todavía hasta el final del folio, pero el extracto nos parece suficiente para mostrar este aspecto teatral de la predicación que, como se señala en los textos de retórica influyentes de la época, apela directamente a los afectos del auditorio. En su Retórica eclesiástica, fray Luis de Granada (1775), por ejemplo, describe algunos medios para "dispertar el ánimo del oyente" (221): la exclamación (con el uso de la interjección "oh"), la repetición de interrogantes (224), el uso del apóstrofe. En la cita podemos apreciar cómo Barrenechea utiliza todos estos instrumentos para mover a sus lectores a compadecerse de Rocamila, del mismo modo en que los utilizaba, no cabe duda, en la elaboración de sus sermones.

La retórica de fray Luis de Granada, de gran influjo en Nueva España (Osorio 50) y, podemos inferir, en la América hispana, desarrolla también la teoría de la amplificación, fundamental para la práctica de los affectus, que consiste, de modo general, en una exposición y enumeración que hace razonar al auditorio sin necesidad de la introducción del silogismo propio de la argumentación (Grace 2016: 969)7 . Como veremos más adelante, el exemplum es, por cierto, uno de los recursos predilectos de la amplificatio. Nuevamente, la descripción de los instrumentos del sermón nos habla también de la escritura de nuestro fraile mercedario, cuyo estilo de continuas citas y digresiones cosechó duras críticas por parte algunos lectores ${ }^{8}$; sin embargo, a la luz de retóricas predicativas como la de fray Luis de Granada podemos entender el afán acumulativo de Barrenechea y Albis como propio del sermón.

Otro elemento del sermón que nuestro autor criollo utiliza en la escritura de su crónica es la estructura que consta, primero, de la presentación del thema, una cita del

\footnotetext{
${ }^{6}$ El texto se ha fijado respetando todos los rasgos que tengan una manifestación fonética, y actualizando solo ortografía y signos de puntuación.

${ }^{7}$ Para una profundización sobre la técnica de la amplificatio, remitimos a la imprescindible obra de James J. Murphy (1986), La retórica en la Edad Media. Historia de la teoría de la retórica desde San Agustín al Renacimiento.

${ }^{8}$ José Toribio Medina (1897) había criticado la obra del mercedario calificándola como "una verdadera algarabía, que no tiene más norte que la filosofía que pretende inculcar, reducida a convencernos de que aquí en la tierra todo es miseria y que solo más allá no habrá lágrimas ni pesares" (589). En 1850, José Ignacio Víctor Eyzaguirre (1850) no había diferido del juicio de Medina al describir la obra del mercedario como una obra que narra hechos históricos "pero entretejidos con mil anécdotas que los desfiguran considerablemente" (282). Añade que el autor "se manifiesta en la narración novelesca hasta parecer exagerado. Las descripciones prolijas que hace de algunos objetos, sin duda entonces de preferencia para los chilenos, causan fastidio por su misma minuciosidad" (283). En el siguiente siglo, Miguel Ángel Vega resume la mala crítica que ha recibido Barrenechea del siguiente modo: "La crítica ha juzgado el libro de Barrenechea y Albis que comentamos con unánime severidad. Se le reprocha el escaso interés de la fábula, sus frases rebuscadas e impertinente erudición y la excesiva idealización de los personajes" (101-102).
} 
Evangelio -generalmente en latín- que luego es comentada y en ocasiones también traducida (Iraceburu Jiménez 738). Esta estructura es utilizada por Barrenechea y Albis en distintas partes de su obra como parte de su estrategia persuasiva, sin que necesariamente tenga como último fin la salvación de las almas. Podemos notar que el capítulo cuarto del libro II, por ejemplo, se estructura como un sermón, pues presenta cada una de sus partes, comenzando por la cita principal de la Biblia (thema) que se comenta a continuación: Supra dorsum meum fabricaverunt pecatores; prolongaverunt inequitatem suam. Esta cita se traduce junto con otras que se van utilizando a lo largo del capítulo y se desarrolla una sutil argumentación conducente a reafirmar la importancia de que se logre la paz en Chile para poder evangelizar a los indígenas. El mal que se prolonga, del que habla el salmo, es el de la guerra, que al mantenerse impide que la gracia de Dios llegue al hombre: es el mismo hombre el que la impide. El capítulo-sermón termina con un salmo final (Propter fratres meos et proximos meos loquebar pacem de te: et propter domum Domini Dei nostri quae sivi bona tibi) que cierra el círculo: volvemos a escuchar al profeta, ahora habiendo comprendido el sentido de sus palabras en relación con la guerra de Chile. Con este ejemplo podemos observar que si bien el sermón es un género textual que parece cerrado y estático, en cierto sentido es todo lo contrario, pues es posible utilizar su solemnidad y legitimidad para argumentar los asuntos más diversos?.

Un dispositivo relevante en la obra de Barrenechea y Albis, relacionado estrechamente con la oratoria sagrada, es el carácter profético y providencialista de su obra. Barrenechea y Albis insiste en describir todos los horrores y dificultades que ha vivido el Reino de Chile, argumenta a favor de la refundación de la ciudad de La Imperial, pero sobre todo predice, a partir de la interpretación de diversos pasajes bíblicos, la grandeza del imperio y del monarca a partir del cumplimiento del programa que plantea el fraile:

Pauper sum ego, et in laboribus ainventute mea. Es el pobre que en este Nuevo Mundo más necesita su favor [del rey Carlos II], sus influjos y regias asistencias, sus socorros y limosnas: su Reino triste de Chile. ¿Luego el retorno debido y que promete el oráculo divino es la bienaventuranza de que habla, y el monarca a quien se anuncia, es la majestad de nuestro Carlos II? Dilatará, pues sin duda, los días de su vida y su grandeza, la Majestad Divina (92r).

La promesa de la bienaventuranza para Carlos II va acompañada también de una serie de consejos al monarca para su obtención. Poco antes el fraile había advertido sobre la importancia del temor de Dios para un monarca, pues solo así lograría su grandeza: “eel monarca que es temoroso de Dios será grande y se descollará glorioso y dilatado su imperio entre todas las monarquías del orbe? ¿Y por qué? ¿Por qué? Porque otro no puede ser grande sobre el que teme al Altísimo" (85v). Esta era una función que cumplían los predicadores

${ }^{9}$ Cerdan (2000) afirma: "Podemos ver cómo los predicadores, a partir del sentido literal, podían deslizarse hacia interpretaciones muy personales y expresar sus anclajes ideológicos" (97). 
reales, pero que el fraile asume gustosamente desde los confines del imperio ${ }^{10}$. Después de prometer la bienaventuranza al monarca, Barrenechea y Albis despliega, con la técnica de la amplificatio en los siguientes capítulos (31 al 38) y hasta terminar el libro, el anuncio de tiempos de paz y prosperidad en La Imperial. La principal fuente bíblica que utiliza el fraile para anunciar "perpetua alegría" para los imperiales es una cita de Isaías 35, en la que se anuncia, después del apocalipsis, la salvación de quienes siguen a Dios. La promesa divina también se alcanzará en los territorios de La Imperial, explica el fraile:

Agora, que para que estas dulzuras todas que anunció Isaías y que habían de gozarse en el Principado de nuestro amoroso Redemptor fuesen también ideadas, como se han ido viendo en otras partes del orbe, y son las que se han de ver, con el favor de los cielos, en La Imperial y sus amenos campos, herencia o heredad que, como queda dicho, le ha dado su eterno Padre en el gentilismo de aquellos términos de la tierra (93v).

Este carácter augural que vemos en su discurso está en concordancia con el espíritu de la época, pues "aunque la tradición profética se remontaba mucho tiempo atrás y estaba profundamente arraigada en la población, en el siglo XVII se vio fuertemente revitalizada" (Morte Acín 2005: 336). Los vaticinios no solo referían a la salvación del alma, sino que también a asuntos más profanos y podían incluso guiar decisiones políticas: "las profecías referidas a temas políticos solían aumentar en momentos especialmente críticos para la Monarquía" (Morte Acín 338). Podemos observar que Barrenechea y Albis entronca con esta tradición muy en sintonía con su época, y urde de modo muy hábil información de carácter histórico, anécdotas y conocimientos bíblicos para reforzar la idea de refundar la ciudad austral debido a las ventajas estratégicas, políticas y también espirituales a los indígenas y al mismo monarca.

\section{Predicación y Exemplum}

La utilización de la retórica y las estrategias del sermón a lo largo de la crónica nos lleva a considerar también la novela intercalada en relación con este discurso. No es

\footnotetext{
${ }^{10}$ Fernando Negredo (1994) señala que, si bien los predicadores reales ya existían antes del reinado de Felipe IV, fue con este que sus funciones se incrementaron y se perpetuaron también en tiempos de su hijo Carlos II, que es a quien se dirige fray Juan (52). La diferencia no menor es que el fraile mercedario no contaba con un auditorio presencial y ni siquiera con la esperanza de que el monarca leyese efectivamente su escrito. Pero aun así fray Juan opera aquí como un predicador real en las funciones que le atribuye Negredo: "el encargado de explicar la palabra divina se convertía, entonces, en el interlocutor que ponía en contacto los designios divinos con las realidades terrenas, mostrando al monarca, verdadero destinatario de la prédica, las directrices que, emanadas del cielo, quería se siguiesen" (61). Es de notar que, más allá de su función religiosa, la instancia de la predicación al rey fue instrumentalizada políticamente, en particular en la época de Felipe IV (Negredo 1994: 88).
} 
de extrañar que Barrenechea y Albis devenga, por momentos, de cronista a predicador, al emplear el discurso novelesco como auxiliar catequético -emulando a un Cristo formulador de parábolas- $\mathrm{y}$, además, al instalar textualmente el fenómeno predicativo en la narración de los amores entre los indígenas Carilab y Rocamila, protagonistas de la novela. Y es que si la novela toda se pretende como elemento probatorio de la necesidad y provecho de la conversión del mapuche, esta solo se logrará -a nivel de anécdota- gracias a un convencimiento por medio de la palabra y la acción. El poder de la prédica, en definitiva, queda demostrado en un claro juego metapredicativo: en el exemplum narrado por Barrenechea, será tras el encuentro y diálogo con el personaje de fray Bartolomé de Vivero que Carilab accederá al bautismo. El programa catequético del mercedario, su discurso pastoral, se ve reproducido, así, en el actuar del religioso antes mencionado, que comparte con nuestro cronista un mismo principio: el requerimiento voluntario del sacramento ${ }^{11}$. La novela "Aventuras y galanteos de Carilab y Rocamila" no es, desde esta lectura, un simple relato de un lance bélico-sentimental: supeditado dicho lance a un propósito religioso y político -la conversión del infiel como hecho clave para alcanzar la pacificación de Araucola novela emerge como todo un exemplum a lo divino en su ejercicio de persuasión sobre los beneficios de la adopción del cristianismo para el Reino de Chile.

En definitiva, al ponderar el hecho literario desde su adscripción al ars praedicandi, se evidencia cómo la novelística chilena en sus orígenes, y en particular la producción letrada en torno a la guerra de Arauco echó mano de la oratoria sagrada. Y cómo desde ella pretendió dar solución a problemáticas particulares de la situación de frontera. En otras palabras, el modus dicendi de Juan de Barrenechea y Albis obedece a su condición de catequista que aprovecha las virtualidades literarias del sermón, confiriéndole una forma novelesca sin traicionar los fines tradicionales de la predicación: agradar, instruir y persuadir.

No es de extrañar, más allá de su condición sacerdotal, que Barrenechea recurra a la retórica del sermón -y al exemplum como modalidad particular- cuando quiere dar forma discursiva a la promoción del cambio de las políticas de la guerra, pero de un modo que evita polemizar agresivamente sobre dicho asunto. $Y$ es que el sermón, en su combinación de persuasión y deleite, emerge idóneo para un debate de ideas recubierto de ficción novelesca, para un discurso militante idealizado acorde también con el espíritu de

\footnotetext{
${ }^{11}$ Muy en la línea, por lo demás, de los planteamientos de un Francisco de Vitoria o un fray Luis de León: "Durante los cursos de 1567-1568 y 1568-1569, fray Luis impartió la materia De Fide, en la que incluyó por primera vez dos disquisiciones sobre la licitud del uso de la violencia en la conquista de las Indias, textos que se mueven plenamente en la esfera del pensamiento de Francisco de Vitoria. Para el maestro de la escuela de Salamanca, como para fray Luis, la fuerza no puede ser justificada por el carácter de «infieles» de los indios, puesto que estos no habían tenido nunca noticia del Evangelio. Por tanto, sus pecados no podían ser argumentados como atentados contra una fe que no conocían. Por otra parte, tampoco estaban los indígenas obligados a aceptar inmediatamente el cristianismo, pues ello sólo indicaría una falsa conversión de conveniencia. Solo una predicación mediante el ejemplo y no mediante las armas, lenta, paciente y pausada, los obligaría a aceptar el bautismo" (Moreno y Martos 1999: xviii-xix).
} 
un catolicismo colonizador ${ }^{12}$. Será a través del discurso indirecto -ejemplar-de la novela de amores mapuche que Barrenechea elabore su polémica visón de la guerra en Chile.

Desde la lectura que proponemos, "Aventuras y galanteos de Carilab y Rocamila", este actúa como un relato de corte fantasioso con claros propósitos ilustrativos y probatorios, como una más de aquellas narraciones de tipo ejemplar a las que el sermón echa mano con frecuencia ${ }^{13}$. Es el relato ficcional, en definitiva, una prueba retórica en torno a los beneficios de la conversión pacífica de los infieles. El propio Carilab, protagonista de la novela, es testimonio del alcance del ars praedicandi, gracias a la palabra efectiva y misionera del fraile mercedario Bartolomé de Vivero que lo induce a la conversión. Lo anterior, muy en la línea de un Cristo entendido como modelo de predicadores, que “...confirmó y reforzó la práctica judía del uso de las Escrituras como prueba; distinguía escrupulosamente entre parábolas y discurso 'directo', entre evangelización (anuncio) y enseńanza (exposición de la doctrina) y hacía constantes comparaciones de lo terreno y lo divino, mediante analogías y metáforas" (Murphy 282). El exemplum actúa, aquí, más allá de su innegable adscripción al discurso religioso, hasta el punto de llegar a ser un hecho estético identificado con la primera novela colonial chilena.

La novela sobre Carilab y Rocamila cumple del todo con las características que la crítica suele atribuir al exemplum:

...son nueve las características provisionales (es una definición abierta) que debe tener un exemplum: carácter narrativo; brevedad; presentación como veraz y auténtico; dependencia relativa respecto a la totalidad del discurso; inclusión en un sermón o texto de tipo homilético; su objetivo ha de ser la persuasión; ha de existir una relación entre un locutor y su auditorio; didactismo; la finalidad última de la pedagogía del exemplum no es sólo la buena conducta o el divertimiento o la felicidad terrestre del auditorio, sino su salvación eterna (Sánchez 1999: 95).

Si entendemos el discurso cronístico en su totalidad como un gran sermón sobre la conveniencia de la evangelización en miras de la convivencia pacífica entre mapuche y españoles, como el marco que da sentido a las palabras ejemplares de la narración, la novela respondería a una singular forma probatoria, enmarcada en el recurso de la amplificatio, ya aludido, como un instrumento auxiliar de la predicación, a modo de fábula o parábola

\footnotetext{
${ }^{12}$ En "El taller del predicador”, Pedro Cátedra (1998) se refiere al “...carácter cambiante, proteico y hasta provisional de esta modalidad del discurso religioso" (293).

${ }^{13}$ Señala Pérez (2011): "El ejemplo es en principio una comparación de carácter narrativo, es decir, que en tanto argumento del discurso el ejemplo toma su carácter probatorio o ilustrativo de una causa expositiva gracias a la comparación de la misma con un asunto externo pero similar a dicha causa; esta función ilustrativa por comparación concentra las posibilidades didácticas del relato al plantear una enseñanza con base en un paradigma moral, en donde es posible observar también su función social en tanto que el relato incluye una propuesta paradigmática de uno o varios modelos de virtud a seguir o bien muestra el castigo derivado de infringir las leyes religiosas, naturales o civiles" (18).
} 
(Bizzarri 2008: 208). En ella, se distinguen claramente, como era de esperar, los modelos positivos y negativos de comportamiento: Carilab, por un lado, y el rebelde Maltaro, por el otro, como en tan buena asociación fónica sugiere su nombre. Y ello, revestido de un relato amoroso, idóneo para mover los afectos, como se espera de todo buen predicador. El propio cronista es el que explicita el carácter probatorio, ejemplar, del relato. En el capítulo IV del Libro Primero, por ejemplo, intitulado "Persuade la restauración de La Imperial y conversión de las almas del gentilismo del Reino de Chile la conquista del vellocino dorado. Y prosíguese la historia”, Barrenechea y Albis recurre a un exemplum de carácter mitológico -la conquista del vellocino de oro- para referirse a la conveniencia y urgencia de que los príncipes cristianos vayan a la conquista del alma, como si de ese anhelado vellón se tratase; empresa que, como la de Jasón y los argonautas, se presentará constantemente obstaculizada y a la que, como los míticos seres, están llamados para “...deshacer encantos y supersticiones vanas..." (7v). Hazaña prodigiosa y equiparable a la de estos conquistadores, en el decir de Barrenechea, y en la que insiste a lo largo de la crónica. Pero en este mismo capítulo, de pronto la narración mítica griega es interrumpida para dar paso y retomar el otro relato ejemplar, esta vez de carácter local, que refuerza el mismo llamado a la gesta evangelizadora. De modo rotundo lo señala el mercedario: "Compruébase lo traído con los sucesos de la historia que llevamos" (85), una historia que no es otra que la de los amores y desventuras de Carilab y Rocamila; su incorporación, como la del relato mitológico griego, se explica en función de su beneficio probatorio, con la diferencia de que en el exemplum protagonizado por los amantes mapuche la ilusión de realidad es mayor, pues se enmarca en una geografía reconocible y con personajes que -si bien responden a la idealización novelística característica de la época y de raigambre áurea- se construyen desde un orbe indiano. De ahí, pues, que parte de la crítica se haya detenido en discutir la veracidad o no del relato, cuestión que aquí no nos interesa abordar ${ }^{14}$.

Barrenechea y Albis se configura no como cualquier predicador, sino como uno criollo. No sorprende, por ello, que el exemplum aparezca insuflado de color local. Como ha demostrado Juan Vitulli (2013), "en las últimas décadas del siglo XVII el grupo criollo está en proceso de crear la figura de un agente cultural inédito, el predicador criollo, a través de ciertas estrategias de negociación discursiva entre su lugar de enunciación y la autoridad peninsular" (417). Es desde ahí, entonces, que leemos la novela sobre Carilab y Rocamila como la versión "dulcificada" de una compleja construcción ideológica que implica polemizar con las prácticas de la corona y la Iglesia españolas. Y es que la oratoria

\footnotetext{
${ }^{14}$ El artículo de Miguel Donoso Rodríguez (2016) recogido en la bibliografía entrega una excelente síntesis de esta polémica. Como señalábamos, no se trata de una discusión a la que queramos entrar en esta oportunidad, no solo por escaparse de los objetivos de este artículo; también porque suscribimos las palabras de Manuel Pérez (2018) en Exempla novohispanos del siglo XVII: "En este sentido, más allá de la verdad y la ficción, conviene preguntarnos por el carácter poético de todos los relatos ejemplares, tanto los históricos como los ficcionales, porque, como ya se vio, para el siglo XVII todos son usados no solo como prueba o ilustración de verdaderos doctrinales, sino también como amplificación y ornato del discurso, de modo que se conducen con naturalidad hacia el deleite" (50-51).
} 
sagrada, como continúa Vitulli, se irguió en la cultura barroca americana como “... una de las herramientas simbólicas y materiales cruciales utilizadas para diseñar, reglar y disciplinar los espacios y sujetos coloniales" (417). En definitiva, será un saber retórico importado de la metrópoli -y vinculado con lo sagrado- el apropiado políticamente por enunciadores criollos, como es el caso del propio fray Juan de Barrenechea y Albis. Como su contemporáneo neogranadino fray Martín de Velasco en su Arte de sermones para hacerlos $y$ predicarlos (1677), Barrenechea se perfilará como intelectual y predicador criollo "...a través de una sutil estrategia discursiva que utiliza ciertas particularidades geográficas y culturales como medio para distinguir al sujeto criollo tanto de los letrados peninsulares como de los otros presentes en la ciudad barroca americana" (418). Así se comprende, creemos, que sobre la base de moldes narrativos peninsulares dé forma a un relato con etnias y geografías locales, pensando en un público no necesariamente criollo y sí, muy probablemente, metropolitano. No debe olvidarse, además, que habla desde Lima sobre los confines del Imperio español. Como intelectual criollo evidenciará una dualidad ideológica, en el decir de Mabel Moraña (1988), que le llevará, por un lado, a asumir la ideología del colonizador, al tiempo que denunciará la mala administración de los gobernantes, de letrados e incluso del clero ${ }^{15}$. Es la suya, según José Anadón, la predicación de una "utopía misionera"; por ello "...Barrenechea se opone a la solución política de los problemas del protagonista. Se declara enfáticamente contra la razón de estado, y diserta largo contra esa vieja teoría de gobierno, hija de Giovanni Botero. Criticará las acciones de Carilab cuando cree que lo empujan consideraciones políticas. El fin del relato es espiritual, y termina con la conversión de la pareja araucana al cristianismo. En todo caso, la política indígena cede a la política cristiana" ("Huellas de tradiciones..." 207), en esa exaltación de la disposición del buen indígena a la evangelización.

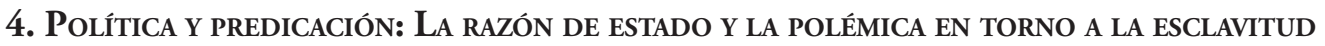

Hemos visto cómo el predicador criollo utiliza la novela como exemplum con fines políticos, de modo que para finalizar quisiéramos dar algunas pistas sobre cuáles son estos asuntos sobre los que Barrenechea y Albis intenta influir a través de su texto de cuño predicativo. La relación entre la oratoria sacra y la política no es nueva, y la destaca Fernando Negredo del Cerro (1994) al señalar que "es bien sabido la importancia que la oratoria sagrada tenía con vistas a crear un estado de opinión sobre determinados temas.

\footnotetext{
${ }^{15}$ Muy en la línea, por lo demás, de lo que Carlos M. Gálvez Peña (2014) señala sobre el discurso religioso y representación política en el Perú del siglo XVII, quien reclama nuevas miradas a las formas retóricas religiosas por su imbricación con la política del Virreinato: "En la historia de la representación política virreinal poca atención se ha prestado a ciertos géneros del discurso religioso que constituyen legítimas fuentes para el estudio de las agendas políticas de las elites urbanas e intelectuales de los reinos americanos" (172). Con respecto al sermón, este será particularmente revelador como objeto de estudio sobre todo a partir de 1630, cuando se aprecie una creciente politización de su contenido (186).
} 
Un rápido vistazo a los principales acontecimientos políticos del siglo XVII (Guerra de los Treinta Años, Revolución Inglesa, La fronda...) así lo demuestran, y no es difícil encontrar a clérigos justificando o atacando ciertos comportamientos políticos" $(58)^{16}$. El sermón es un discurso poderoso e influyente, así como quien lo enuncia: "[e]l predicador asume el poseer el monopolio de la crítica a cualquier nivel" (62). Nuestro autor mercedario parece conocer muy bien las posibilidades persuasivas de la retórica predicativa y las utiliza de modo hábil para trenzar un discurso que, como veremos, está en plena concordancia con las preocupaciones de la época.

La novela de Carilab y Rocamila que se encuentra intercalada en el texto de Barrenechea debe entenderse, como hemos dicho, en el marco del objetivo final del texto que es, como ya apuntara José Anadón, el de "promover la creación de una comunidad entre espańoles e indígenas que vivan en paz y justicia" (Anadón 1988b: 174), comunidad que debe ser cristiana y estar sometida a la corona. A través de la incorporación de la novela de amores mapuche, Barrenechea y Albis releva el lugar de la conversión y del matrimonio en tanto sacramento cristiano como centrales para la consecución de la paz. Ello no es solo, postulamos, un mero acto de imaginación novelesca, sino que una afirmación política que implica una crítica a las soluciones que proponen terminar con la guerra a través del conflicto bélico. Barrenechea y Albis buscan restablecer el sentido evangélico de la conquista en un contexto en donde los problemas se han vuelto otros: la legitimidad o conveniencia de esclavizar a los mapuche, las diferencias entre criollos y espańoles. Queremos argumentar que Barrenechea y Albis no solo buscar ejercer influencia en el desarrollo de las políticas con respecto a la Guerra de Arauco, sino que interviene en dos importantes polémicas del debate público del siglo XVI: una de ellas de impronta más local, que refiere a la esclavitud de los mapuche, y la otra de carácter transatlántico, concerniente al impacto de la obra de Nicolás Maquiavelo en la forma de concebir un gobierno.

José Anadón llama la atención sobre cómo Barrenechea y Albis problematiza la polémica entre la así llamada razón de estado y el ideal del príncipe cristiano. El fraile “...trata de demostrar que el concepto de 'razón de estado' (que entiende por "un recto conoscimiento de medios aptos para conservar y ampliar los Reynos y Monarchias") es antagónico a los intereses cristianos..." (Anadón 1988b: 184). Las reflexiones de Barrenechea y Albis remiten a vivas polémicas que arreciaron en la vida intelectual en España durante el siglo XVII a propósito de la recepción y discusión de Maquiavelo. Su propuesta de separar la moral y la religión de las decisiones políticas a favor de la conservación del poder fue resistida por muchos intelectuales españoles, como Pedro de Rivadeneira, quienes propusieron una razón de estado cristiana que intentaba conciliar la defensa de la religión con el pragmatismo necesario para defender los intereses del Estado. En los siglos XVI al XVIII "la España Moderna estuvo signada por dos debates: el del descubrimiento y conquista de América y el ocasionado por la colisión entre realismo político moderno y

\footnotetext{
${ }^{16}$ Para Negredo, los sermones "son pieza clave que hacen adoptar a multitud de personas unos comportamientos y unas actitudes mentales que hubiesen sido incapaces de tomar sin la intervención de un eclesiástico" (63).
} 
la moral cristiana” (Ruiz 2013: 772). Estas discusiones abstractas entraron muchas veces en tensión con las decisiones tomadas por los monarcas españoles, como fue el caso de las paces firmadas con herejes anglicanos y calvinistas ante el aumento de gastos de la guerra y la imposibilidad de conseguir una victoria. Las paces de Vervins (1598) firmadas con Francia por Felipe II y luego las de su hijo Felipe III con Inglaterra (Tratado de Londres, 1604) y con los Países Bajos (Tratado de Amberes 1609), fueron criticadas por intelectuales que consideraban estas capitulaciones como una victoria de las doctrinas de Maquiavelo (Díaz Blanco 2009: 272). La guerra en Chile también era onerosa para la corona, y al igual que con las potencias europeas, el monarca español se decantó por la idea de promulgar las paces con los araucanos a través de la Guerra Defensiva propiciada por Luis de Valdivia. Esta se apuntalaba en un derecho aceptado en la época, que era el de rebelarse en contra de la tiranía. Para los mapuche, la tiranía se encarnaba, en esta lectura, en el servicio personal que debían sufrir (Díaz Blanco 281). La desaparición del servicio personal traería la paz y la posibilidad de evangelizar, reforzando así los dos pilares fundamentales para el gobierno: la paz y la justicia (Díaz Blanco 280): "de todas las paces que firmó la Corona española a lo largo del siglo XVII, solo la de Chile consiguió los parabienes de los católicos radicales al ser identificada como fruto de la Razón de Estado cristiana” (Díaz Blanco 285).

El interés de Barrenechea y Albis por la razón de estado se enmarca en esta polémica entre maquiavelistas y antimaquiavelistas propia del desarrollo de las ideas políticas hispanas del siglo XVII y propone su propia postura que, si bien por un lado reafirma la importancia de la defensa de la religión para la consecución de la paz y el buen gobierno, por otro elabora unos argumentos y una estrategia persuasivas que podríamos considerar sui generis.

Pero las preocupaciones de Barrenechea y Albis tienen también un anclaje local. Para dimensionar bien esta proyección de su discurso, recordaremos algunas características del contexto chileno en el siglo XVII y el rol de la orden mercedaria en él. El siglo se abre con el gran alzamiento indígena de 1598 y la creación, a consecuencia de este, del ejército permanente y asalariado en 1603. La actividad guerrera de este siglo fue la maloca, cuyo objetivo era la obtención de un botín, que eran los mismos indígenas, en especial mujeres y niños, para ser tomados como esclavos. Durante este período se promulgó una real cédula el 26 de mayo de 1608 que autorizaba la esclavitud de los indios de guerra. Los trece años en que duró oficialmente la Guerra defensiva (1612-1626) y la defensa del indígena, realizada por el jesuita Torres Bollo, fueron una excepción (Prieto 2013: 71). La maloca fue un mecanismo para la obtención de esclavos (Jara 1971: 144-145), y ya fuera en la práctica como legalmente a partir de $1608^{17}$, la esclavitud indígena fue tema principal no solo a principios de siglo, como reacción a la muerte de García Oñez de Loyola y por la polémica implementación de la política de la guerra defensiva, sino que a lo largo de todo el siglo hasta su prohibición definitiva en 1679. La prohibición no terminó, sin embargo, con la necesidad de contar con mano de obra ni tampoco con una cultura de la esclavitud tan arraigada en la sociedad española, de modo que "los hispano-criollos de Chile desplegaron

${ }^{17}$ Real cédula de esclavitud de los indios de guerra de las provincias de Chile, 26 de mayo de 1608. 
una serie de argumentos para no cumplir este mandato [la Real cédula del 12 de junio de 1679]" (Obregón y Zavala 2009: 17). A pesar de que a partir de mediados del siglo XVII disminuyen los conflictos armados y se pasa a la práctica de la maloca y de los parlamentos (Villalobos 1985), la guerra de Arauco sigue teniendo un rol fundamental en los escritos de este siglo, pues si bien adquiere otras formas sigue siendo un hecho fundamental de la vida política, económica y social.

La importancia de la guerra y la esclavitud puede observarse también en la escritura de diversos textos que, a lo largo del siglo, abordan el tema. Hay cuatro que justifican la esclavitud indígena y que, según Álvaro Jara, pueden considerarse hitos con respecto a la discusión sobre la esclavitud a principios de siglo: el tratado del licenciado Melchor Calderón, redactado en 1599 como reacción a la muerte de García Ońez de Loyola; el texto del dominico fray Reginaldo de Lizárraga; el de fray Juan de Vascones y el de Domingo de Erazo (1602). También el libro del Alonso González de Nájera (1614) aboga por la esclavitud de los indígenas "para lo que toca a la libertad que defienden, que el mundo no bien informado les justifica, digo que estos bárbaros, además de que no defienden religión, pues no guardan ninguna, no es razón que se les abone la libertad que defienden, por ser libertad bestial" $(567)^{18}$. Pero estas preocupaciones también se ven mucho en los decenios que siguen, e incluso mucho más allá de la abolición de la esclavitud: "[u]na sociedad que giró durante tantos años y hasta tal punto en torno a la esclavitud indígena resistiría inevitablemente al ver que la prohibición de la esclavitud se confirmaba" (Obregón y Zavala 16). La prohibición no cambió el hecho de que los territorios al norte del Bío-Bío contaran con una mano de obra escasa, mientras que en el sur había población indígena "disponible" que no podía ser explotada a través de la encomienda por hallarse en zonas no controladas por los hispanos (Obregón y Zavala 17). La mano de obra tenía que ser arrancada de su territorio y trasladada a otros lugares, es decir, las personas apresadas como esclavos y comercializadas.

Barrenechea y Albis fue testigo de esta época agitada que conoció a través de su trabajo misionero y también en su calidad de habitante de una ciudad fronteriza. En Concepción, Barrenechea y Albis presenció, por ejemplo, una liberación de cautivos que habían sido capturados en el gran alzamiento de 1598. Si bien los mercedarios no destacaron en las discusiones con respecto a la esclavitud ${ }^{19}$, los testimonios que conservamos respecto de su posición sobre la guerra de Arauco son coincidentes en el apoyo a la política de la guerra ofensiva, su crítica a Luis de Valdivia y su justificación de la esclavitud mapuche. Ya

\footnotetext{
${ }^{18}$ Nájera propone que, para evitar su rebelión, estos esclavos sean vendidos al Perú (p. 643 y ss).

${ }^{19}$ Cfr. P. Morales Ramírez (1983): "Finalmente, como hombres que estuvieron en el lugar de los hechos, llama la atención que no sobresalieron en las disputas en que se vieron ocupados muchos religiosos de otras órdenes; pero esto no fue por la ignorancia de los hechos, sino más bien ellos evitaron estas disquisiciones teóricas porque o no tenían tiempo o las consideraron utópicas y su experiencia les enseñaba otra cosa; sin embargo, tendremos la ocasión de referirnos a opiniones que aquellos dieron especialmente al Rey, relacionadas con los problemas de la guerra de Arauco; el mercedario se caracterizó más por lo que hizo que por lo que dijo" (61).
} 
en la reunión que se sostuvo en 1599 en la catedral de Santiago, en la que Melchor Calderón solicita la esclavitud de los indígenas cuenta con la participación del mercedario Francisco de Rivero ${ }^{20}$. Más adelante, en 1614, el también capellán mercedario Juan de Tovar redacta desde Concepción un informe dirigido al rey en donde declara: "su Religión [La Merced] es partidaria de la guerra ofensiva, ya que la experiencia lo seńala así, pues los sucesos que se han ofrecido se verifican el no ser posible otra cosa” (citado en Morales 226). También se pronuncia a favor de la guerra defensiva el capellán mercedario Francisco Ponce de León (Morales 1983: 226) en una obra publicada en 1644 y, un poco más tarde, en 1663 la misma postura es refrendada por el Provincial Ramón de Morales; finalmente, un informe de 1671 que registra los resultados de una reunión en la que se reitera la necesidad de la esclavitud indígena y en la que participa el padre mercedario Juan de la Cruz Astorga (Morales 136). Vemos, así, que la postura de la orden se mantuvo en sintonía con la de los encomenderos, como puede deducirse, por ejemplo, de este extracto del informe de fr. Ramón de Morales:

Mi parecer es, Señor, que no solo los Indios, que han sido de guerra desde la destrucción de las siete Ciudades, y muerte del Gobernador Martín García de Loyola, y que después gobernando este Reino el Marqués de Baides, dieron las paces fingidas, sean esclavos, si no es lo que deben ser por las mismas causas, y aun por otras más urgentes todos los Yanaconas, así de encomiendas, como de reducciones que se rebelaron en el Gobierno de D. Antonio de Acuña y Cabrera, como fuesen cogidos en la Guerra (citado en Morales 421).

Morales se refiere aquí a los mapuche que se rebelaron en 1598 y a los que firmaron las paces de Quilín (o de Baides) en 1641. Los primeros fueron esclavizados en virtud de la cédula de 1608, en la que se justificaba la esclavitud con la actitud de rebeldía de los indígenas en contra del poder real. Por la misma época en que redactaba estas palabras, Diego de Rosales terminaba su Manifiesto apologético de los daños de la esclavitud del reino de Chile en el que, si bien no condenaba globalmente la esclavitud, sí argumentaba que el alzamiento de 1655 no era en contra de la fe ni en contra del rey, sino que contra la crueldad y abusos cometidos por el gobernador Acuna y Cabrera; por lo tanto, la justificación que se daría para la esclavitud de los indígenas en la cédula de 1608 no tendría validez en este caso (Prieto 2013: 78). El texto de Morales no solo disiente de este argumento temporal, sino que proclama la esclavitud tanto de los indios de guerra como de los encomenderos y yanaconas. El religioso afirma que los indígenas no se han podido educar "por la resistencia, y odio, que esta Nación rebelde tiene a nuestra santa fe, pues en esto más que en otra causa, funda la enemistad, que se ha conocido tener a los españoles" (Morales 421). Finalmente, termina con una condena general y permanente hacia todos los indígenas con las siguientes palabras:

\footnotetext{
${ }^{20}$ Pocos años más tarde se publica un breve texto en el que Calderón expone los argumentos esgrimidos en relación con la discusión sobre la legitimidad de la esclavitud en dicha reunión: Tratado de la importancia y utilidad que hay en dar por esclavos a los indios rebelados de Chile (Madrid, 1607).
} 
...las experiencias largas nos enseñan la poca estabilidad de su fe en la obediencia, lo ajeno que tiene su natural de las cosas tocantes a la divina ley, pues en todo lo que he experimentado no he hallado indio, que se pueda decir verdadero cristiano, porque aunque reciben el agua de bautismo, juzgan que es ceremonia introducida por algún engaño nuestro, y aquella fe, que los hizo del gremio de la Iglesia yace muerta, no solo por la falta de obras, con que vive, sino es por la multiplicidad de actos contrarios en todo género de vicios, tales que aun en los brutos se pensaran escandalosos (422).

Los mercedarios estuvieron, pues, involucrados también en la polémica de la esclavitud, y, como señala Morales Ramírez, "en general la posición de la orden fue la de alinearse por el sistema de la guerra ofensiva, será única en el transcurso de ella" (226). Años más tarde de estas palabras del provincial, Barrenechea y Albis termina una crónica en la que disiente de esta postura.

La novela de Carilab y Rocamila pretende ofrecer una solución imaginaria al problema de la esclavitud y del buen gobierno, que era tanto económico, moral, político como judicial. No es casualidad que Barrenechea cite largamente, en el noveno capítulo del primer libro de la crónica, la cédula real al Virrey del Perú que refiere a la guerra ofensiva. El autor cita dicho documento -que ordena la vuelta de la guerra ofensiva y la esclavitud de los indígenas cogidos en guerra- para insistir en que la esclavitud solo se justificaba a ojos del rey en los prisioneros de guerra, rechazando la práctica de cacería o maloqueo de piezas con fines comerciales. Por otro lado, al terminar la cita Barrenechea y Albis argumenta que las culpas de los españoles no han permitido el establecimiento de una paz definitiva en el reino $(21 \mathrm{r}-\mathrm{v})$. De este modo, el mercedario relaciona el problema de la guerra y del buen gobierno con el cumplimiento de la voluntad divina. Solo la vida piadosa y fiel de los españoles, solo la consecución de la misión evangelizadora puede terminar con la guerra.

Hemos visto cómo fray Juan pretende intervenir en discusiones teóricas sobre la razón de Estado e influir sobre el desarrollo de la guerra. Los medios de persuasión que utiliza para ello están en concordancia con su objetivo, pues debe mover los corazones, sensibilizar los sentidos y a la vez que hacerse cargo de los argumentos de carácter legal, económico o político de sus adversarios. El fraile mercedario echa mano a su experiencia como predicador utilizando una batería de estrategias discursivas y figuras retóricas de larga tradición que ha adquirido durante su formación religiosa y que deben de haber sido familiares a sus lectores. Uno de los rasgos más notorios del texto de Barrenechea es el relato intercalado de la historia de Carilab y Rocamila que toma la forma de una novela o romance. Este relato no solo ha captado el interés de la crítica moderna, sino que también fue objeto de atención durante la época colonial. La novela entretiene y ayuda, al estar intercalada a lo largo de todo el texto, a mantener despierto el interés del lector. Pero también es una manera astuta de introducir personajes indígenas y sensibilizar a los lectores, probablemente criollos, sobre la postura discutida respecto de la guerra en Chile. El uso de la retórica del sermón contribuye, como vemos, a plantear la postura de la evangelización del indígena 
como una tarea urgente, y la única verdaderamente efectiva para terminar con el conflicto bélico de larga data y de difícil solución.

\section{ObRas CITADAS}

Adorno, Rolena. 1990. "New Perspectives in Colonial Spanish American Literary Studies”. Journal of the Southwest 32.2: 173-191.

Anadón, José. 1983. "Estudio preliminar". La novela colonial de Barrenechea y Albis (siglo XVII). Aventuras y galanteos de Carilab y Rocamila. Santiago: Universitaria.

. 1988a. "Huellas de tradiciones narrativas (Heliodoro, Villegas y Ercilla) en el Carilab y Rocamila". Historiografía literaria de América colonial. Santiago de Chile: Ediciones Universidad Católica de Chile. 204-243.

. 1988b. "Novela colonial: utopía misionera y tratamiento de los personajes indios en Barrenechea y Albis". Historiografía literaria de América colonial. Santiago de Chile: Ediciones Universidad Católica de Chile. 173-203.

. 2017. "El idilio indianista en Carilab y Rocamila". En Grínor Rojo, Carol Arcos, Stefanie Massmann, coord., Historia critica de la Literatura chilena. Volumen I. La era colonial. Santiago: Lom. 235-241.

Barrenechea y Albis, fray Juan de. 1693. Restauración de La Imperial y conversión de almas infieles. (Ms.) Archivo Nacional de Chile, Fondo Antiguo vol. 39.

Bizzarri, Hugo. 2008. "La Biblia en la prosa homilética y moral de la Edad Media”. En María Isabel Toro Pascua, coord., La Biblia en la literatura española. I. Edad Media. I/2. El texto: fuente y autoridad, Madrid: Trotta. 195-252.

Cátedra, Pedro. 1998. "El taller del predicador. A propósito de un sermón castellano para el Domingo de Ramos (RAE, Ms 294)". En José María Soto Rábanos, coord., Pensamiento medieval hispano. Homenaje a Horacio Santiago-Otero (separata)._Madrid: Consejo Superior de Investigaciones Científicas Consejería de Educación y Cultura de la Junta de Castilla y León. 291-320.

Castaño Navarro, Ana. 2008. "Sermón y literatura. La imagen del predicador en algunos sermones de la Nueva España”. Acta Poética 29.2: 191-212.

Cerdan, Francis. 2000. “Oratoria sagrada y reescritura en el Siglo de Oro: el caso de la homilía”. Criticón 79: 87-105.

Chinchilla Pawling, Perla. 2004. De la Compositio Loci a la República de las letras. Predicación jesuita en el siglo XVII novohispano. México: Universidad Iberoamericana.

Díaz Blanco, José Manuel. 2009. La guerra defensiva: confesionalidad y "maquiavelismo" de la política española en Chile. Chronica Nova: revista de historia moderna de la universidad de Granada 35: 267-285.

Donoso Rodríguez, Miguel. 2016. "Sangre y estirpe al otro lado del Atlántico: la historia de los amores de Carilab y Rocamila, un relato contenido en la crónica Restauración de La Imperial y conversión de las almas infieles, de Juan de Barrenechea y Albis”. En 
García Hernán, David y Miguel F. Gómez Vozmediano, eds., La cultura de la sangre en el Siglo de Oro. Madrid: Sílex. 349-367.

Eyzaguirre, José Ignacio Víctor. 1850. Historia eclesiástica, política y literaria de Chile. Tomo II. Valparaíso: Imprenta Europea.

Gálvez Peña y Carlos M. 2014. "El mejor arbitrio, el sermón». Discurso religioso y representación política en el Perú del siglo XVII". Anuario de Estudios Americanos 71.1: 171-197.

González de Nájera, Alonso. 2017. Desengaño y reparo de la guerra del Reino de Chile. Ed. Miguel Donoso Rodríguez. Santiago de Chile: Universitaria.

Grace, Carmen M. 2016. "Sobre la 'predicación culta` en el siglo de Oro: polémicas y retóricas cristianas". BHS 93.9: 964-980.

Granada, fray Luis de. 1775. Los seis libros de la retórica eclesiástica, escritos en latín por el V. P. M. fr. Luis de Granada, vertidos en españoly dados a luz de orden y a costa del ilustrísimo señor Obispo de Barcelona, para instrucción de sus feligreses con destino de producto al socorro de su seminario Episcopal. Barcelona: Imprenta de Juan Jolis y Bernardo Plá.

Herrejón Peredo, Carlos. 1994. "La oratoria en Nueva España". Relaciones 57: 57-80.

Iraceburu Jiménez, Maite. 2016. "Metáforas y contexto social en sermones del siglo XVIII". Principe de Viana 265: 733-756.

Jara, Álvaro. 1971. Guerra y sociedad en Chile. Santiago: Universitaria.

Martínez, Lucía. 2015. Rasgos morfosintácticos en el español de Chile del s. XVII: análisis del manuscrito inédito 'La restauración de La Imperial y conversión de las almas infieles' de Juan de Barrenechea y Albis (1693). Tesis para optar al grado de Magíster en Lingüística mención Lengua Espańola, Universidad de Chile.

Massmann, Stefanie y Rocío Rodríguez. 2015. "Amores mapuche en la frontera de Chile: usos y funciones del relato amoroso en La restauración de la Imperial y conversión de las almas infieles (h. 1693), de Juan de Barrenechea y Albis”. En Miguel Donoso, ed., Mujer y literatura femenina en la América virreinal. Nueva York: IDEA.

Medina, José Toribio. 1897. Biblioteca hispano-chilena (1523-1817). Tomo I. Santiago: En casa del autor.

Menéndez y Pelayo, Marcelino. 1943. Orígenes de la novela II. Santander: CSIC.

Morales Ramírez (O. de M.) y P. Alfonso A. 1983. Historia General de la Orden de La Merced en Chile (1535-1831). Santiago de Chile: Empresa Industrial gráfica.

Moraña, Mabel. 1988. "Máscara autobiográfica y conciencia criolla en Infortunios de Alonso Ramirez, de Carlos Sigüenza y Góngora". Viaje al silencio. Exploraciones del discurso barroco. México, D.F.: Facultad de Filosofía y letras. Universidad Autónoma de México. 217-230.

Moreno Mengíbar, Andrés y Juan Martos Fernández. 1999. "Estudio preliminar". Fray Luis de León. Escritos sobre América. Madrid: Tecnos.

Morte Acín, Ana. 2005. "Profetas en la Corte de Felipe IV: Aragón, testigo privilegiado (1643-1648)". La monarquía hispánica en tiempos del Quijote. Coord. Porfirio Sanz Camañes. Madrid: SL. 
Murphy, James J. 1986. La Retórica en la Edad Media. Historia de la teoría de la retórica desde san Agustín hasta el Renacimiento, trad. Guillermo Hirata Vaquera, México: Fondo de Cultura Económica.

Negredo del Cerro, Fernando. 1994. "Levantar la doctrina hasta los cielos: el sermón como instrumento de adoctrinamiento social". En Martínez Ruiz y Vicente Suárez Grimón, eds., Iglesia y sociedad en el Antiguo Régimen. Vol. I. Enrique. Universidad de Las Palmas de Gran Canaria. . 2001. "Política e Iglesia. Los predicadores de Felipe IV". Memoria para optar al grado de Doctor. Madrid: Universidad Complutense de Madrid, Facultad de Geografía e Historia, Departamento de Historia. https://eprints.ucm.es/4324/1/ T25118.pdf Consultado el 10-01-2019.

Obregón Iturra, J.P. y J. M. Zavala Cepeda. 2009. "Abolición y persistencia de la esclavitud indígena en Chile colonial: estrategias esclavistas en la frontera araucano-mapuche". Memoria Americana 17.1: 11-35.

Osorio Romero, Ignacio. 1980. Floresta de gramática, poética y retórica en Nueva España (1521-1767). México D.F.: Universidad Nacional Autónoma de México.

Pérez, Manuel. 2011. Los cuentos del predicador. Historias y ficciones para la reforma de costumbres en la Nueva España. Madrid: Iberoamericana Vervuert. 2018. Exempla novohispanos del siglo XVII. Madrid: Iberoamericana Vervuert.

Prieto, Andrés. 2013. Manifiesto apologético de los daños de la esclavitud del Reino de Chile. Santiago de Chile: Catalonia.

Ruiz, Julio Juan. 2013. "Nicolás Maquiavelo en el pensamiento político del Siglo de Oro español”. Revista de estudios histórico-jurídicos 35: 771-781.

Sánchez, Manuel Ambrosio. 1999. Un sermonario castellano medieval. El Ms. 1854 de la Biblioteca Universitaria de Salamanca. 2 vols. Salamanca: Ediciones Universidad de Salamanca.

Vega, Miguel Ángel. 1980. Historia de la Literatura Chilena de la Conquista y de la Colonia. Tomo II. Santiago: Nascimento.

Villalobos, Sergio. 1985. "Guerra y paz en la Araucanía: periodificación”. En Villalobos, Sergio y Jorge Pinto, ed. Araucanía. Temas de historia fronteriza. Temuco: Universidad de la Frontera.

Vitulli, Juan. 2013. "Construyendo al predicador criollo: una aproximación al 'Arte de sermones’ de fray Martín de Velasco”. Hispanic Review 81.4: 417-438.

Witschorik, Charles A. 2013. Preaching Power: Gender, Politics and Official Catholic Church Discourses in Mexico City, 1720-1875. Eugene: Pickwick Publications. 
